\title{
Negative Chemical Ionization in Quadrupole Ion Trap Mass Spectrometry: Effects of Applied Voltages and Reaction Times
}

\author{
D. W. Berberich* and R. A. Yost \\ University of Florida, Department of Chemistry, Gainesville, Florida, USA.
}

\begin{abstract}
The effects of applied voltages and reaction times on negative ion chemical ionization in the quadrupole ion trap are investigated. Mass-selected ejection of undesired reagent ions and selective mass storage of only negative ions are required for practical negative ion chemical ionization. This is achieved by application of if and dc voltages to the ring electrode to control the mass-to-charge ratios (one polarity) of ions stored, as well as by application of a supplemental if voltage applied across the endcap electrodes to selectively eject ions of a particular mass-to-charge ratio. Even with careful control of these parameters, negative chemical ionization is not as sensitive as electron ionization and positive chemical ionization because of the lack of thermal electrons in the ion trap. Mass selection of the hydroxide anion as a reagent ion and exclusion of all positive ions provide $[\mathrm{M}-\mathrm{H}]^{-}$ions with little or no fragmentation for a wide variety of compounds. (J Am Soc Mass Spectrom 1994, 5, 757-764)
\end{abstract}

$\mathrm{T}$ he quadrupole ion trap mass spectrometer (QITMS) [1] has enjoyed a renaissance as a sensitive, small, and low cost instrument for gas chromatography-mass spectrometry (GC-MS) [2]. The ability to mass select and store ions under computer control provides remarkable versatility with few if any instrumental modifications, including such features as low-pressure chemical ionization [3-6] and tandem (in time) mass spectrometry [7-9]. The combination of these capabilities to perform mass-selected chemical ionization permits careful control of the type of ionization and the energies of the ionization process (and hence the extent of fragmentation) that takes place in the ion trap $[4,10-25]$.

Although the vast majority of these studies have employed positive ions, limited studies of negative ions have been reported $[5,6,17,25-30]$. McLuckey et al. [5] briefly described the formation of $[\mathrm{OH}]^{-}$and $[\mathrm{O}]^{-}$negative chemical reagent ions in a QITMS for ionizing organic compounds with a high electronegativity. Parameters governing the injection of reagent ions for negative chemical ionization from an external source into a QTTMS also have been published [31]. Nevertheless, the experimental parameters necessary for successful negative chemical ionization (with reagent ion formation within the ion trap) in the QITMS have not been addressed in detail. Here we report the characterization and optimization of reaction times and

\footnotetext{
Address reprint requests to Richard A. Yost, Department of Chemistry, University of Florida, Gainesville, Florida 32611.

"Current address: Mallinckrodt Chemicals, P.O. Box 5439, St. Louis, MO 63147.
}

applied voltages that are critical for the formation and detection of negative ions in the QITMS. Negative ion formation via both electron capture and negative ion-molecule reactions [negative chemical ionization (NCI)] are discussed.

The research presented here centers on the use of various electrical fields applied to the ion trap to control the mass range and polarity of ions that have stable trajectories, as well as the kinetic energy of these ions. These fields include the fundamental $\mathrm{rf}$ voltage applied to the ring electrode, a supplemental rf voltage applied across the endcap electrodes at the secular frequency of ions of a specific mass-to-charge ratio, and a dc voltage applied to the ring electrode to provide isolation of ions of a specific mass [4, 10-25, 28-30] or a particular polarity $[26,28]$. These capabilities provide the opportunity to carefully control the type of ionization that takes place in the ion trap, and the energetics of ionization (and hence the degree of fragmentation). It is also demonstrated how these approaches are required to make NCI within the ion trap a practical technique.

The results of the evaluation of several operational modes and the parameters that affect these operation modes (e.g., applied voltages and reaction times) for negative ionization in the QITMS are examined. Non mass-selected and mass-selected ion-molecule reactions are discussed. Some of the time intervals that will be addressed are ionization time, reactant ion formation time, and sample ion formation time. Three modes of operation will be explored: rf-only mode (nonmass-selected reactions), rf voltage and supplemental rf voltage (mass-selected ejection of unwanted reactant 


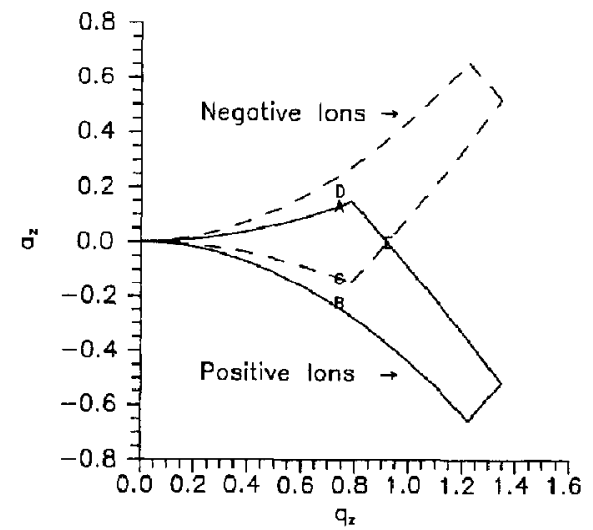

Figure 1. Mathieu stability envelopes for positive (solid line) and negative (dashed line) ions. Points $A, B, C, D$, and $E$ have corresponding $a_{z}$ values of $0.134,-0.223,-0.133,0.176$, and 0.00 , and $q_{z}$ values of $0.738,0.738,0.738,0.738$, and 0.908 .

ions), and if and dc voltage plus supplemental if voltage (mass-selected reactions). The basic forms of the scan functions for the various modes of operation are described in the experimental section. Conclusions and suggestions for future negative ionization studies with the QITMS are also presented.

\section{Mathieu Stability Diagram}

A plot of the regions of stability in $a$ and $q$ space that provide theoretical stable trajectories is called a stability envelope [32,33] of the Mathieu type and is shown in Figure 1 [26]. The ions with values of $a$ and $q$ that lie within the stability envelope will have stable trajectories. Conversely, all ions with values of $a$ and $g$ that lie outside the stability envelope will have unstable trajectories and will not be stored in the ion trap. The solid and dashed lines in Figure 1 represent the stability envelopes for positive and negative ions, respectively. It is readily apparent from examination of the stability envelopes that by operation of the ion trap with appropriate values of $a$ and $q$, ions of a single polarity (negative or positive) can be stored in the ion trap. Mather and Todd [26] first demonstrated this capability by using a dc pulse to isolate the $[\mathrm{Cl}]^{-}$ions from dissociative electron capture of dichloromethane. This isolated polarity region was explored with the experiments that follow.

\section{Experimental}

\section{Samples and Reagents}

Helium (zero grade) buffer gas was obtained from Liquid Air Corporation (San Francisco, CA). Sulfur hexafluoride (high purity) was obtained from Matheson (Secaucus, NJ). Phenyl acetonitrile, methyl ben- zoate, ethyl benzoate, aniline, nitrobenzene, and benzamide (all high purity) and 0 -cresol (practical grade) were obtained from Chem Service (West Chester, l'A). Glycine (ammonia-free crystalline), benzoic acid (certified ACS grade), and $n$-butyl benzene (98\% pure) were obtained from Sigma Chemical Co. (St. Louis, $\mathrm{MO}$ ), Fisher Scientific (Orlando, FL), and Eastman Kodak (Rochester, NY), respectively.

\section{Quadrupole Ion Trap Mass Spectrometry}

The quadrupole ion trap mass spectrometer (QITMS) used in these studies was a Finnigan MAT (San Jose, CA) ion trap mass spectrometer (ITMS), which was operated at $100 \mathrm{C}$. The He buffer gas was introduced directly into the ion trap via a variable leak valve (Granville-Phillips, Inc., Boulder, $\mathrm{CO}$ ). The reactant gases $\left(\mathrm{N}_{2}, \mathrm{Ar}, \mathrm{CO}_{2}, \mathrm{~N}_{2} \mathrm{O}, \mathrm{CH}_{4}, \mathrm{C}_{2} \mathrm{H}_{4}\right.$, and $\mathrm{SF}_{6}$ ) were introduced into the vacuum chamber of the QITMS through the normal reactant gas lines via a fine metering valve (Negretti Valve Division, Southampton, England) while $\mathrm{H}_{2} \mathrm{O}$ reactant gas was introduced via a variable leak valve (Granville-Phillips), each at indicated chamber pressures between 1.0 and $2.0 \times 10^{-5}$ torr. All liquid samples were introduced into the vacuum chamber through a variable leak valve (Granville-Phillips) mounted on a 1/2-in.-o.d. probe inserted through the solids probe inlet assembly to yield indicated chamber pressures of $2.0 \times 10^{-6}$ torr (the end of the sample probe was approximately $2.5 \mathrm{~cm}$ away from the ion trap). All solid samples were introduced into the vacuum chamber by means of a standard solids probe inserted through the solids probe inlet assembly (the end of the sample probe was approximately $2.5 \mathrm{~cm}$ away from the ion trap). All pressures are uncorrected, as measured with a Bayard-Alpert ionization gauge (Granville-Phillips) mounted on the vacuum chamber.

The standard dynode and channeltron electron multiplier assembly was modified to permit detection of negative ions. This modification involved the removal of the resistor between the dynode and the multiplier. The dynode was then connected to a separate external high-voltage power supply (Bertan, Hicksville, NY), which left the electron multiplier voltage under computer control of the QITMS. Typical dynode voltages were $+3 \mathrm{kV}$ for negative ion detection and $-3 \mathrm{kV}$ for positive ion detection. Electron multiplier voltages were typically $-2.2 \mathrm{kV}$ for negative ion detection and $-1.6 \mathrm{kV}$ for positive ion detection. In general, the obtained negative ion spectra were very weak in intensity; hence, more gain on the multiplier was required to obtain reasonable quality spectra. Unless otherwise noted, the conversion dynode was biased for negative ion detection in these studies.

The scan diagrams for the scan modes used for ionization in the QTTMS are shown in Figures 2 and 3. The first approach, mass-selected ejection chemical ionization (CI), involves the application of a supplemental rf voltage across the endcap electrodes at the resonant 


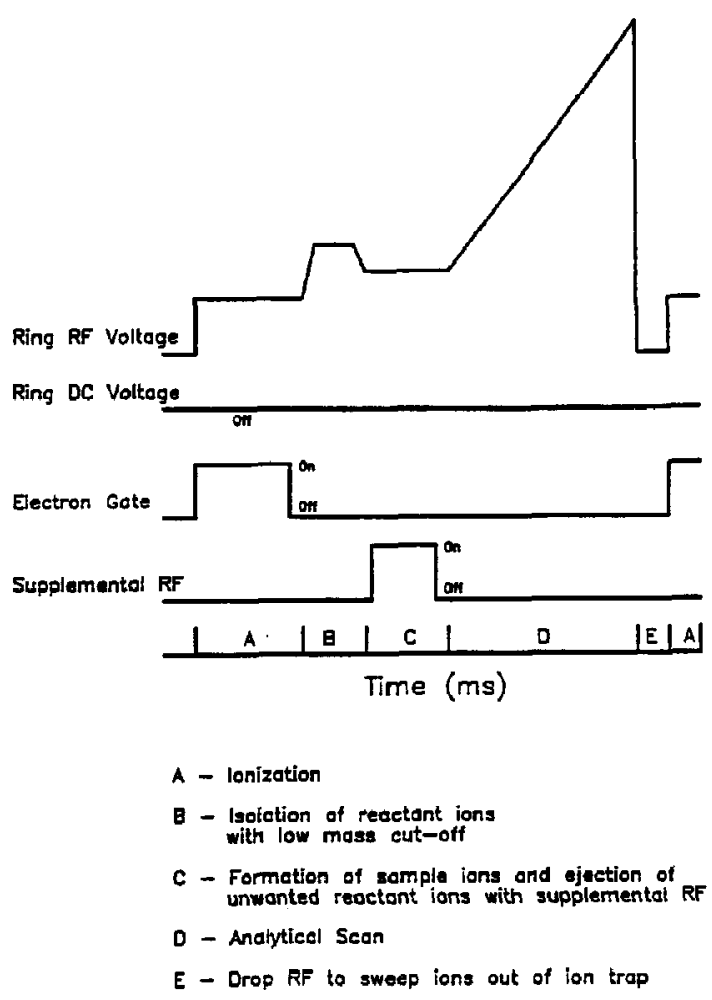

Figure 2. QITMS scan function for mass-selected ejection.

frequency of a particular mass-to-charge ratio ion during the sample ion formation reaction period (Figure 2). Provided that the magnitude of this supplemental rf voltage is large enough, an undesired ion (reactant or product) can be ejected from the ion trap, thereby preventing it from increasing in abundance during a reaction time (reaction ion or sample ion formation).

The second approach, mass-selected reactions, employs a dc voltage applied to the ring electrode in conjunction with the $\mathrm{rf}$ voltage during the reactant ion isolation step (period B, Figure 3). This allows a narrow range of mass-to-charge ratios (typically $1 \mathrm{u}$ wide) to have stable trajectories within the ion trap [8]. This mode of operation is analogous to a quadrupole mass filter [32]. Thus, the products of any ion-molecule reactions that occurred during previous periods, but are not in the mass-to-charge ratio range of interest, can be ejected from the ion trap. The ability to massselect ions of a single mass-to-charge ratio enables specific ion-molecule reactions to be monitored. All of the mass spectra shown represent a single analytical scan (each is the average of seven microscans).

\section{Results and Discussion}

\section{Electron Capture}

Electron capture (EC) is an ionization process that normally requires electrons of thermal or near-thermal

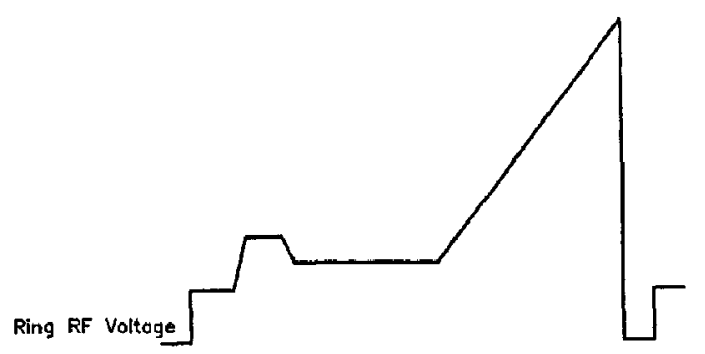

Ring DC Voltoge

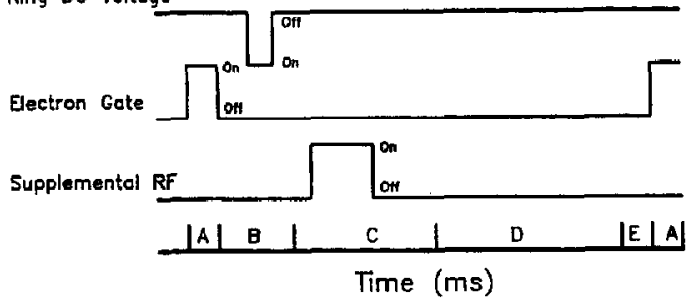

$$
\begin{aligned}
& \text { A - Ionization } \\
& \text { B - Isalation of reactant ions with DC } \\
& \text { C - Formation of somple ions and ejection of } \\
& \text { unwanted reactant ions with supplemental RF } \\
& \text { D - Analytical scan } \\
& \text { E - Drop RF to sweep ions out of ion trop }
\end{aligned}
$$

Figure 3. QITMS scan function for mass-selected reactions.

energy. The three basic reactions that can lead to negative ions upon interactions of an electron with a neutral molecule [34] are electron capture, dissociative electron capture, and ion-pair productions. All of the EC processes are resonance processes because no electron is produced to carry away the excess energy. These processes are observed for electrons with kinetic energies from thermal up to $\sim 15 \mathrm{eV}$ [35].

For this work, EC was the first mode of operation that was characterized. A number of reactant gases were examined for the production of thermal electrons, including methane, water, ammonia, nitrous oxide, carbon tetrachloride, and sulfur hexafluoride. The sample compounds examined for EC were $n$-butyl benzene, nitrobenzene, and benzoic acid. Electron capture was not observed for any of the sample molecules examined, although dissociative electron capture was observed for some reagent gases. Even if electrons could undergo enough thermalizing collisions at the low pressures $(\sim 1000$ times lower than in conventional CI sources) in the ion trap, they would still not reach thermal energies, because the rf field will impart new kinetic energy to the electrons. Indeed, electrons have a mass-to-charge ratio thousands of times lower than the low mass-to-charge ratio cutoff of the ion trap. As a result, electrons will have unstable trajectories and much too short a residence time in the ion trap to be thermalized [36].

When the QITMS was operated to detect negative ions, positive ions were also detected. This discovery 
was first suggested by the observation of $m / z 19$, $\left[\mathrm{H}_{3} \mathrm{O}\right]^{+}$, in the negative ion mass spectrum of water, and confirmed by studies in which $\left[\mathrm{H}_{3} \mathrm{O}\right]^{+}$was eliminated by operation of the trap in a stability region where all positive ions are unstable (point $D$ in Figure 1). When the QITMS is configured for negative ion detection, a conversion dynode biased at $+3000 \mathrm{~V}$ functions by converting negative ions to positive ions by impact on its surface [37]. The positive ions are accelerated to the negatively biased electron multiplier and are detected in the usual manner. Positive ions may be detected during negative ion operation either by bypassing the $+3000-\mathrm{V}$ conversion dynode and directly striking the multiplier (held at $-2400 \mathrm{~V}$ ) or by striking the endcap or multiplier shield surfaces after being repelled by the conversion dynode, which produces electrons or negative ions that can then be detected.

The most significant time parameters for the production of negatively charged reactant ions via dissociative electron capture are the times for ionization, application of dc voltage (applied to the ring electrode), and mass-selective ejection of abundant positive reagent ions (e.g., $\left[\mathrm{H}_{3} \mathrm{O}\right]^{+}$from water). The characterization and optimization of dc voltage applied to the ring electrode for isolation of the reactant ion requires consideration of the Mathieu stability envelopes for positive and negative ions (Figure 1), In positive mass-selected CI, the ion trap is typically operated near the apex of the stability envelope (point $A$, negative dc voltage applied to the ring electrode) for positive ions. When the ion trap was operated at the apex of the stability diagram for negative ions (point $C$, positive dc voltage applied to the ring electrode), high intensities of ions at $\mathrm{m} / \mathrm{z} 57$ and 135 were observed (Figure 4a), which actually correspond to $\left[\mathrm{C}_{4} \mathrm{H}_{9}\right]^{+}$and $\left[\mathrm{C}_{10} \mathrm{H}_{15}\right]^{+}$or $[\mathrm{M}+\mathrm{H}]^{+}$for $n$-butyl benzene, respectively, and not to negative ions. These ions are presumably formed under positive $\mathrm{CI}$ by $\left[\mathrm{H}_{3} \mathrm{O}\right]^{+}$. The lack of negative ions is due to positive-negative ion recombination, because both the abundant positive and less abundant negative ions have stable trajectories in the ion trap at this point. Alternatively, when the ion trap was operated with negative dc voltages applied to the ring electrode (point $D$ above the apex of the stability diagram for positive ions), efficient isolation of negative ions was obtained (Figure $4 \mathrm{~b}$ ). With the application of $-18-\mathrm{V}$ dc to the ring electrode (with a constant $q_{z}$ of 0.738$),[\mathrm{OH}]^{-}$at $m / z 17$ will have an $a_{z}$ value corresponding to 0.171 (point $D$ on the stability diagram). At this value of $a_{z}$ a fairly wide mass range $(\sim 15 \mathrm{u})$ of negative ions are efficiently stored in the ion trap, whereas positive ions are not. Hence, the problems associated with positive ion-negative ion recombination are eliminated. Therefore, for the isolation of negative ions, negative dc voltages were applied to the ring electode.

Figure 5 illustrates the characterization of dc voltage applied to the ring electode for $[\mathrm{OH}]$ ion isola-
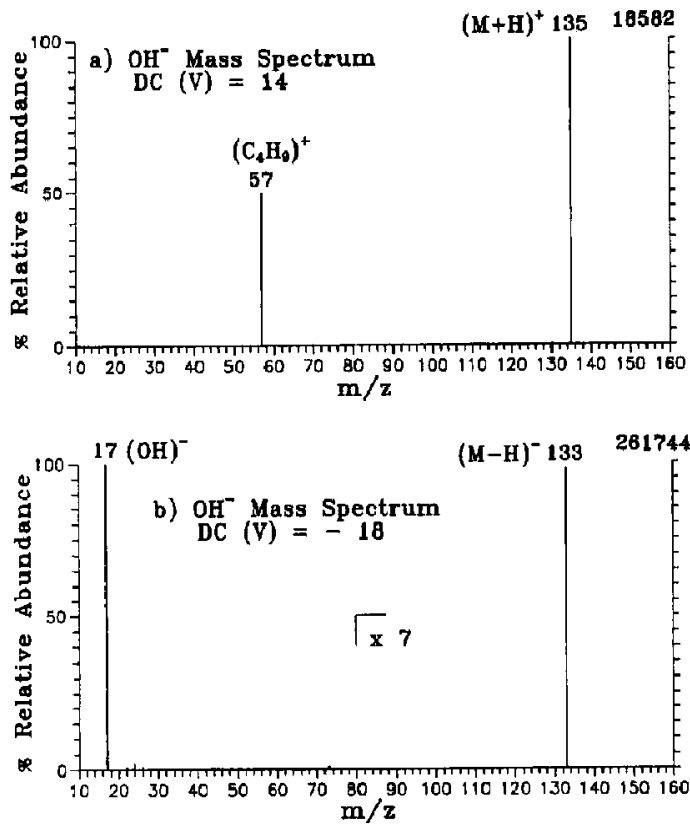

Figure 4. The $[\mathrm{OH}]^{-}$mass-selected NCI mass spectra of $n$-butyl benzene (MW 134) with dc voltages of (a) +14 V $\left(a_{z}=-0.133\right)$ and (b) $-18 \mathrm{~V}\left(a_{z}-0.171\right)$ and a constant $q_{2}$ value of 0.738 for $m / z 17$.

tion, with other parameters held constant. When dc voltages applied to the ring electrode are more negative than approximately $-18 \mathrm{~V}\left(a_{z}>0.171\right)$ following ionization, negative ions (Figure 5a) are observed at very high intensities, whereas positive ions (Figure $5 b$ ) are largely eliminated. Once again, with positive $\mathrm{dc}$ voltages applied to the ring electrode, some positive ions are still detected in the negative ion spectra (Figure $5 b$ ). The dc voltage applied to the ring electrode at which the positive ions are decreased to less than $10 \%$ of their maximum intensities, at which point $\mathrm{m} / \mathrm{z} 17$ is attenuated to one half its maximum intensity (i.e., -18 V), was used in the next optimization study.

Some of the reactant gases and reactant gas systems examined were water, nitrous oxide, carbon tetrachloride, sulfur hexafluoride, and 50/50 mixtures (by pressure) of nitrous oxide and water and of nitrous oxide and methane [38]. It is clear from these experiments that negative ion isolation with negative dc voltages applied to the ring electrode is very efficient. Reactant ions $[\mathrm{OH}]^{-},[\mathrm{Cl}]^{-}$, and $\left[\mathrm{SF}_{6}\right]^{-}$(produced from $\mathrm{H}_{2} \mathrm{O}$, $\mathrm{CCl}_{4}$, and $\mathrm{SF}_{6}$, respectively) were isolated for $\mathrm{NCI}$ experiments. The mass spectrum of the $\left[\mathrm{Cl}^{-}\right.$reactant ion from $\mathrm{CCl}_{4}$ shows a ${ }^{35} \mathrm{Cl}$ to ${ }^{37} \mathrm{Cl}$ isotope ratio of 15 , compared to the normal value of 3 , that is due to the ejection of the ${ }^{37} \mathrm{Cl}$ isotope [25].

\section{Negative Chemical lonization}

Negative ion-molecule reactions may occur by a number of different processes, which include proton ab- 

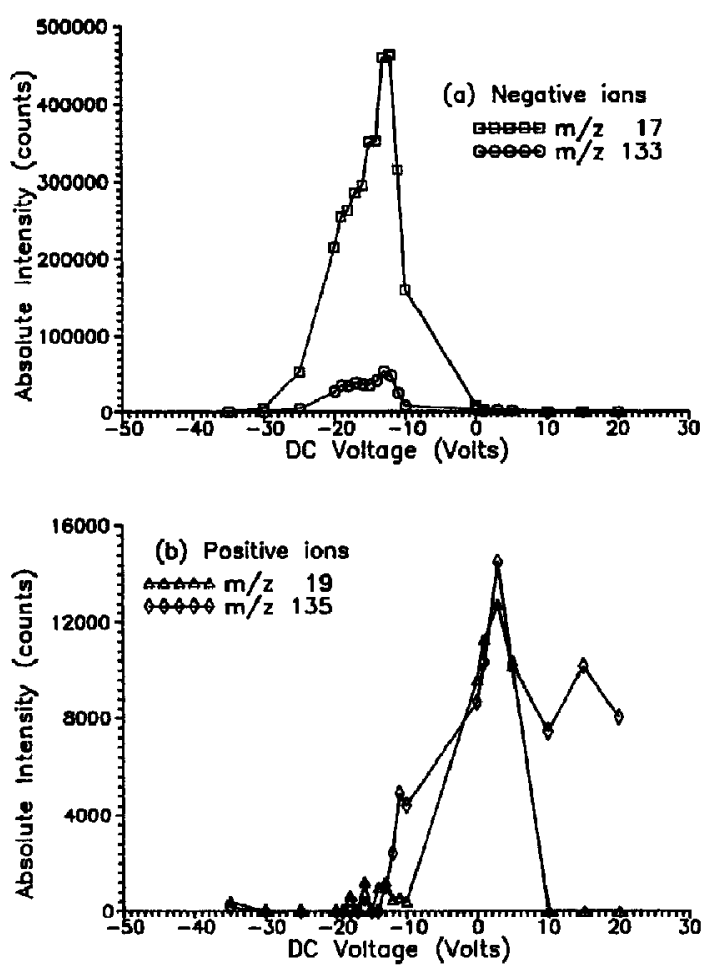

Figure 5. Effect of dc voltage on the storage of various ions in the water $\mathrm{NCI}$ mass spectrum of $n$-butyl benzene: (a) $[\mathrm{OH}]^{-}$, $m / z 17$, and $\left[\mathrm{M}-\mathrm{H}^{-}, m / z 133\right.$ and $(\mathrm{b})\left[\mathrm{H}_{3} \mathrm{O}\right]^{+}, m / z 19$, and $[\mathrm{M}+\mathrm{H}]^{+}, m / z 135$.

straction, charge exchange, nucleophilic addition, and nucleophilic displacement, that produce primarily $[\mathrm{M}-\mathrm{H}]{ }^{-},[\mathrm{M}],[\mathrm{M}+\mathrm{R}]^{-}$, and $[\mathrm{M}-\mathrm{H}]^{-}$ions, respectively [35]. This article will address only proton abstraction reactions in the ion trap. These reactions are well known and are described in detail in a number of previous works [25, 39-41]. Hydroxide ion $[\mathrm{OH}]^{-}$is one of the most commonly used reactant ions in NCI [42]. The $[\mathrm{OH}]^{-}$ion from water can be produced in high-pressure ion sources by dissociative electron capture to form $[\mathrm{H}]^{-}$, followed by proton abstraction from another $\mathrm{H}_{2} \mathrm{O}$ molecule to form $[\mathrm{OH}]^{-}$ [43]. Note that $[\mathrm{H}]^{-}$is of such low mass-to-charge ratio that it will not be stored in the ion trap, which makes the formation of $[\mathrm{OH}]^{-}$via this route improbable. In low-pressure ionization sources, the $[\mathrm{OH}]^{-}$ reagent ions may be formed via dissociative attachment reactions, with cross sections $10-10^{4}$ times lower than those for the production of $[\mathrm{H}]^{-}[44]$. In [OH ${ }^{-}$ $\mathrm{NCI}$, the major reaction that transpires is $[25,41]$

$$
\begin{gathered}
{[\mathrm{OH}]^{-}+\mathrm{M} \rightarrow[\mathrm{M}-\mathrm{H}]^{-}+\mathrm{H}_{2} \mathrm{O}} \\
\Delta \mathrm{H}=\mathrm{PA}\left(\left[\mathrm{M}-\mathrm{H}^{-}\right)-\operatorname{PA}\left([\mathrm{OH}]^{-}\right)\right.
\end{gathered}
$$

The reactant gases examined for negative chemical ionization (NCI) were water, carbon tetrachloride, and sulfur hexafluoride. The samples examined for $\mathrm{NCI}$ were glycine, aniline, $o$-cresol, phenyl acetonitrile, benzoic acid, nitrobenzene, $n$-butyl benzene, methyl benzoate, benzamide, and ethyl benzoate.

Mass-Selected Ejection. In the mass-selected ejection mode a supplemental $\mathrm{rf}$ voltage is applied across the endcap electrodes at the resonant frequency of ions of a particular mass-to-charge ratio. This procedure will prevent an ion of that mass-to-charge ratio from being stored in the ion trap provided the amplitude and application time of the voltage are sufficient to rapidly increase the amplitude of the ion trajectory until it exceeds the ion trap dimensions.

The major difference in the scan functions for positive chemical ionization (PCI) and $\mathrm{NCI}$ is that with $\mathrm{NCI}$ the maximum formation of the negative reactant ions (e.g., $[\mathrm{OH}]^{-}$) occurs during the ionization time (filament-on time), whereas with PCI the maximum formation of positive reactant ions (e.g., $\left[\mathrm{H}_{3} \mathrm{O}\right]^{+}$) requires a reaction time after the ionization time. The main factor that contributes to this appears to be positive ion-negative ion recombination that quickly eliminates the less abundant negative ions. The other factor is that to attain reasonable sensitivity, ionization times for $\mathrm{NCI}$ are 100-1000 times longer than those for PCI. Hence, in $\mathrm{NCI}$, ion-molecule reactions to form negative reactant ions can occur during the relatively long ionization times (60-100 ms).

The important operating parameters for massselected ejection $\mathrm{NCI}$ are ionization time $(60-100 \mathrm{~ms})$, the amplitude of the supplemental $\mathrm{rf}$ voltage ( $3 \mathrm{~V}$ ) used for mass-selected ejection of the major positive reactant ion (e.g., $\left[\mathrm{H}_{3} \mathrm{O}\right]^{+}$at $m / z$ 19), and the reaction time to form sample ions ( $60-200 \mathrm{~ms})$. As mentioned previously, optimum ionization times (to form reactant ions) are between 60 and $100 \mathrm{~ms}$, which is much longer than with PCI (ionization times are typically between 0.1 and $1 \mathrm{~ms}$ ). The necessity of long ionization times for mass-selected ejection can be readily explained. The EC process, even the dissociative EC process to form reactant ions, is much less efficient due to the lack of thermal electrons, and therefore, longer ionization times are required to produce an adequate number of reactant ions. Another contributing factor to the long ionization times required for formation of $[\mathrm{OH}]^{-}$ reactant ions may relate to the cross sections of the dissociative electron attachment process for water. Melton [44] reported that the cross section for the most common state of water dissociating to $[\mathrm{H}]^{-}$is $4.8-7.6$ $\times 10^{-18} \mathrm{~cm}^{3} /$ molecule, which is much higher than the cross sections for those states that lead to the direct production of $[\mathrm{OH}]^{-}\left(8.5-12 \times 10^{-7)} \mathrm{cm}^{3} /\right.$ mulecule $)$ or $[\mathrm{O}]^{-}\left(1.3-5.7 \times 10^{-19} \mathrm{~cm}^{3} /\right.$ molecule). These low cross sections also may contribute to the long ionization times required for $\mathrm{NCl}$ in the trap.

The characterization of sample ion formation time for mass-selected ejection NCI illustrates that due to the ejection of $\left[\mathrm{H}_{3} \mathrm{O}\right]^{+}$, positive ion interferences are 
Table 1. $\mathrm{OH}^{-}$mass-selected NCI mass spectral summary for the compounds examined

\begin{tabular}{lccc}
$\begin{array}{l}\text { Compound of } \\
\text { inlerest }\end{array}$ & $\begin{array}{c}{[\mathrm{M}-\mathrm{H}]^{-}} \\
(\% \mathrm{RA})^{\mathrm{a}}\end{array}$ & $\begin{array}{c}\text { Fragment } \\
\text { iuris }(\% \mathrm{RA})\end{array}$ & $\begin{array}{c}{[\mathrm{OH}]^{-} \text {remaining }} \\
(\% \mathrm{RA})\end{array}$ \\
\hline \hline Glycine & $74(100)$ & $\mathrm{ND}$ & $(31)$ \\
Aniline & $92(100)$ & $\mathrm{ND}$ & $\mathrm{ND}$ \\
0 -Cresol & $107(100)$ & $\mathrm{ND}$ & $(64)$ \\
Phenyl acetonitrile & $116(100)$ & $\mathrm{ND}$ & $(27)$ \\
Nitrobenzene & $122(100)$ & $92(8)$ & $(6)$ \\
& & $46(91)$ & $(14)$ \\
Benzamide & $120(100)$ & $\mathrm{ND}$ & $(53)$ \\
$n$-Butyl benzene & $133(100)$ & $\mathrm{ND}$ & $(18)$ \\
Benzoic acid & $121(100)$ & $\mathrm{ND}$ & $\mathrm{ND}$ \\
Methyl benzoate & $\mathrm{ND}$ & $121(100)$ & $(11)$ \\
Ethyl benzoate & ND & $121(100)$ & \\
& & $45(29)$ & \\
\hline
\end{tabular}

$\% \mathrm{FA}=$ percent relative abundance.

${ }^{\mathrm{ND}}=$ not detected.

not significant in the mass spectrum of the sample molecules. The non-mass-selected NCI experiments yielded poor results. The negative reactant ions, as well as the more abundant positive ions, are stored in the ion trap. Hence, positive-negative ion recombination leads to rapid loss of the negative ions, which limits the ability to perform $\mathrm{NCI}$ in the ion trap [26]. For example, the spectrum observed for water nonmass-selected NCI of $n$-butyl benzene is shown in Figure 6a. The spectrum is clearly the result of both NCI $\left([\mathrm{OH}]^{-}\right.$reactant ion plus $[\mathrm{M}-\mathrm{H}]^{-}$at $m / z$ 133)
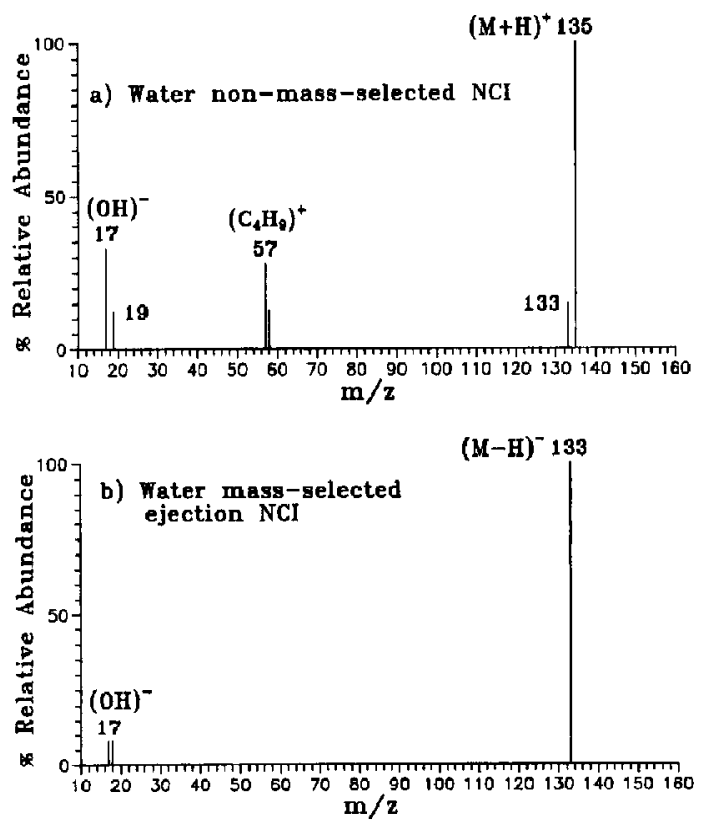

Figure 6. NCI mass spectra of n-butyl benzene (MW 134) (a) water non-mass-selected and (b) mass-selected ejection of $\left[\mathrm{H}_{3} \mathrm{O}\right]^{+}$ with a sample ion formation time of $70 \mathrm{~ms}$. Mass scan range from $m / 215$ to 300 . and PCI $\left(\left[\mathrm{H}_{3} \mathrm{O}\right]^{+}\right.$reactant ion plus $[\mathrm{M}+\mathrm{H}]^{+}$and $\left[\mathrm{C}_{4} \mathrm{H}_{9}\right]^{+}$at $m / z 135$ and 57 , respectively). The optimum sample ion formation reaction time is $70 \mathrm{~ms}$ for water mass-selected ejection NCI of $n$-butyl benzene (Figure 6b), and the spectrum is characterized by an $[\mathrm{M}-\mathrm{H}]^{-}$ion at $m / z 133$ and no fragmentation. Comparison with Figure 6a shows that ejection of $m / z 19$ has prevented formation of any positive ions (e.g., $\mathrm{m} / z$ $135^{+}$), which eliminates the problem of positive ions in the NCI spectrum. The excitation voltage for massselected ejection of $m / z 19\left(\left[\mathrm{H}_{3} \mathrm{O}\right]^{+}\right)$is applied throughout the sample ion formation segment (period $\mathrm{C}$ in Figure 2) with an amplitude of $3 \mathrm{~V}$.

Mass-Selected Ion-Molecule Reactions. The first two parameters (ionization time and isolation of reactant ions) for NCI studies were optimized with the EC experiments. The next parameter that was optimized was reaction time for the formation of sample ions (period $C$ in Figure 3). This study was performed by using the optimum values obtained for ionization time $(60 \mathrm{~ms})$ and isolation (dc voltage of $-18 \mathrm{~V}$ applied for $1 \mathrm{~ms}$ ). The $[\mathrm{OH}]^{-}$mass-selected NCI spectra of all the sample molecules are summarized in Table 1 . The mass spectra (except for those of nitrobenzene and the alkyl benzoates) are characterized by little or no fragmentation and the presence of an intense $[\mathrm{M}-\mathrm{H}]^{-}$ion. Hence, this ionization technique is complementary to PCI and provides molecular weight confirmation for a wide range of compound types. The methyl benzoate and ethyl benzoate $[\mathrm{OH}]^{+}$mass-selected NCI mass spectra both exhibit an intense benzoate anion due to the loss of the alkyl group, but lack any detectable [M $\mathrm{H}^{-}$ion. The ethyl benzoatc mass spectrum also has a fragment ion at $m / z 45$ (either $\left[\mathrm{C}_{2} \mathrm{H}_{5} \mathrm{O}\right]^{-}$or $\left.[\mathrm{HCOO}]^{-}\right)$that is not present in the benzoic acid or methyl benzoate spectra. The $[\mathrm{OH}]^{-}$mass-selected NCI mass spectrum of nitrobenzene is characterized by an abundant $[\mathrm{M}-\mathrm{H}]^{-}$ion $(m / z 122)$ and a $\left[\mathrm{NO}_{2}\right]^{-}$ion $(m / z 46)$, as well as a low abundance ion at $m / z 92$ 
that corresponds to $[\mathrm{M}-\mathrm{HNO}]^{-}$. The optimum $[\mathrm{OH}]^{-}$ mass-selected NCI reaction time to form sample ions was determined to be the point at which the remaining reactant ion intensity was reduced to less than that of the sample ions produced, which corresponded to the point when the ion intensity of $\left[\mathrm{M}-\mathrm{H}^{-}\right.$was maximized. In some cases, indeed all the $[\mathrm{OH}]^{-}$ion is gone, which indicates that the sample ionization time was long enough to use up all the reactant ion. For the $[\mathrm{OH}]^{-}$mass-selected NCI studies, optimum reaction times were on the order of $80-100 \mathrm{~ms}$, dependent on the concentration of the neutral sample.

The 50/50 mixture of $\mathrm{N}_{2} \mathrm{O}$ and $\mathrm{H}_{2} \mathrm{O}$ also produced predominantly $[\mathrm{OH}]^{-}$and some $[\mathrm{O}]^{-}$reactant ions. There appears to be no advantage to the use of this reaction mixture instead of only $\mathrm{H}_{2} \mathrm{O}$ for NCI. Therefore the characterization of this reaction mixture will not be discussed further. The other reactant gases and the corresponding isolated reactant ions that were examined-ammonia $\left(\left[\mathrm{NH}_{2}\right]^{-}\right)$, carbon tetrachloride $\left(\mathrm{Cl}^{-}\right)$, and sulfur hexafluoride $\left(\left[\mathrm{SF}_{6}\right]^{-}\right)$-did not produce negative ions from any of the sample molecules examined in this study. These reactant ions were examined with high-pressure NCI studies and they displayed some reactivity with the classes of compounds examined in this work. For instance, $[\mathrm{Cl}]^{-}$was shown to form adduct ions with nitroaromatic compounds to

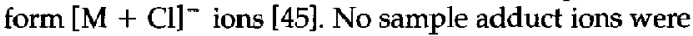
detected with any of these reactant gases, which may be explained readily. In high-pressure ( $\sim$ 1-torr) NCI studies, the reactant and sample ions undergo a number of collisions that can stabilize the negative charge on the respective ions. In contrast, in the ion trap the pressures are 1000 times lower, which makes collisional stabilization unlikely.

\section{Conclusions}

A major theme of this work is the application of various electrical fields to the ion trap to control the mass range and polarity of ions that have stable trajectories. It was demonstrated how these approaches make NCI within the ion trap a practical, albeit not a particularly sensitive, technique. Electron capture is only observed in the ion trap for compounds with extremely high electron affinities (e.g., $\mathrm{SF}_{6}$ ). However, dissociative electron capture is observed in the ion trap for a variety of reactant gases that includes water, ammonia, and carbon tetrachloride. The likelihood of dissociative FC is greater than FC for these species, because it can occur with more energetic electrons.

Negative chemical ionization also is observed to require much longer ionization and sample formation reaction times than does positive chemical ionization, although the tabulated rate constants for NCI and PCI are approximately the same $[25,31,44]$. The need for longer reaction times for negative ionization results from the presence of negative reactant ions in much lower abundance than positive reactant ions, even when the same sample and reactant gas pressures are used. This abundance discrepancy may be due to the lack of thermal electrons in the trap and the lower cross sections for dissociative electron attachment to form the hydroxyl and oxide anions in low-pressure sources.

Positive ions within the ion trap needed to be ejected to prevent positive ion-negative ion recombination trom eliminating the less abundant negative ions. 'This ejection of positive ions from the ion trap for $\mathrm{NCl}$ was achieved either by mass-selectively ejecting the major positive reactant ion (e.g., $m / z 19,\left[\mathrm{H}_{3} \mathrm{O}\right]^{+}$) with the supplementary rf voltage or by ejecting all positive ions with a negative dc voltage applied to the ring electrode. The mass-selected $\mathrm{NCI}$ mode of operation (with dc voltage) is the most effective technique for performing NCI. studies. The results from the QITMS $[\mathrm{OH}]^{-}$mass-selected $\mathrm{NCI}$ studies point out that molecular weight information in the form of abundant $[\mathrm{M}-\mathrm{H}]^{-}$ions can be obtained from a wide variety of compounds, typically with little or no fragmentation.

Future work should include applications for the examination of $\mathrm{NCI}$ for gas chromatographic analysis. Preliminary studies of $[\mathrm{OH}]^{-}$mass-selected $\mathrm{NCI}$ indicate that $\left[\mathrm{H}_{3} \mathrm{O}\right]^{+} \mathrm{PCI}$ is at least a factor of 10 times more sensitive than $[\mathrm{OH}]^{-}$mass-selected NCI [29]. Further work needs to be done in this area utilizing various classes of organic compounds. The ability to obtain PCI $\left([\mathrm{M}+\mathrm{H}]^{+}\right)$and $\mathrm{NCI}\left([\mathrm{M}-\mathrm{H}]^{-}\right)$mass spectra for unknown compounds provides strong evidence for molecular weight confirmation. Future work should also include an evaluation of other methods for the selective storage of $\mathrm{m} / \mathrm{z} 17$ during the ionization step such as the filtered noise field technique developed by Teledyne [46] and the selected ion storage technique developed by Varian [47].

\section{References}

1. Paul, W.; Reinhard, H.; von Zahn, V. Z. Z. Physik 1959, 156, 1.

2. Stafford, Jr., G. C.; Kelley, P. E; Syka, J. E. P.; Reynolds, W. E.; Todd, J. F. J. Int. I. Mass Spectrom. Ion Processes 1984, 60, 85.

3. Bonner, R. F.; Lawson, G.; Todd, J. F. J. I. Chem. Soc. Chem. Commun. 1972, 1179.

4. Brodbclt, J. S.; Louris, J. N.; Cooks, R. G. Anal. Chem. 1987, $59,1278$.

5. McLuckey, S. A.; Glish, G. L.; Kelley, P. E. Anal. Chem. 1987, $59,1670$.

6. Kelley, P. E.; Stafford, Jr., G. C.; Reynolds, W. E.; Louris, J. N.; Todd, J. F. J. Adv. Mass Spectrom. 1985, 10B, 869.

7. Johnson, J. V.; Yost, R. A.; Kelley, P. E.; Bradford, P. C. Anal. Chem. 1990, 62, 2162.

8. Weber-Grabau, M.; Kelley, P. E.; Syka, J. E. P.; Bradshaw, S. C.; Brodbelt, J. S. Proceedings of the 35th Annual Conference on Mass Spectrometry and Allied Topics; Denver, CO, 1987; p 1114.

9. Louris, J. N.; Cooks, R. G.; Syka, J. E. P.; Kelley, P. E.; Stafford, Jr., G. C.; Todd, J. F. J. Andl. Chem, 1987, 59, 1677. 
10. Berberich, D. W. Yost, R A. Presented at the 1987 South East Regional Meeting of the American Chemical Society, Orlando, FL, 1987.

11. Berberich, D. W.; Hail, M. E.; Yost, R. A. Procedings of the 36th Annual Conference on Mass Spectrometry and Allied Topics; San Francisco, CA, 1988; p 1110.

12. Weber-Grabau, M.; Kelley, P. E.; Bradshaw, S. C.; Hoekman, D. J. Proceedings of the 36 th Annual Conference on Mass Spectrometry and Allied Topics; San Francisco, 1988; p 1106.

13. Tucker, D. B.; I lameister, C. [I.; Bradshaw, S. C.; I Ioekman, D. I.; Weber-Grabau, M. Proceedings of the 36 th Annual Conference on Mass Spectrometry and Allied Topics; San Francisco, CA, 1988; p 628.

14. Glish, G. L.; Van Berkel, G. J.; Asano, K. G.; McLuckey, S. A. Proceedings of the 36 th Annual Conference on Mass Spectrometry and Allied Topics; San Francisco, CA, 1988; p 1112.

15. Bradbelt, J. S.; Cooks, K. G. Anal. Chim. Acta 1988, 206, 239.

16. Berberich, D. W.; Hail, M. E.; Johnson, J. V; Yost, R. A. Int. J. Mass Spectrom. Ion Processes 1989, 94. 115.

17. March, R. E.; Hughes, R. Practical Organic Mass Spectrometry: Wiley: New York, 1989

18. Strife, R. J.; Keller, P. R. Org. Mass Spectrom. 1989, 24, 201.

19. Louris, J. N.; Brodbelt-Lustig, J. S.; Cooks, R. G.; Glish, G. L.; Van Berkel, G. J.; McLuckey, S. A. Int. J. Mass Spectrom. Ion Processes 1990, 96, 117.

20. Strife, R. J.; Simms, J. R,; Lacey, M. P. I. Am. Soc. Mass Spectrom. 1990, 1, 265

21. Strife, R. J.; Simms, J. R. J. Am. Soc. Mass Spectrom. 1992, 3, 372 .

22. Donovan, T.; Liou, C. C.; Brodbelt, I. S. I. Am. Soc. Mass Spectrom. 1992, 3, 39.

23. Donovan, T.; Brodbelt, J. S. Biol. Mass Spectrom. 1992, 21, 254.

24. Liou, C. C.; Brodbelt, J. S. I. Am. Chem. Soc. 1992, 114, 6761.

25. Harrison, A. G. Chemfcal Ionization Mass Spectrometry, 2nd ed.; CRC Press: Boca Raton, FL, 1992; p 1.

26. Mather, R. E.; Todd, J. F. J. Int. I. Mass Spectrom. Ion Phys. $1980,33,159$

27. Schermann, J. P.; Major, F. G. Appl. Phys. 1978, 16, 225.

28. Berberich, D. W.; Yost. R. A. Proceedings of the 37th Ammual Conference on Mass Spectrometry and Allied Topics; Miami Beach, 1989; p 1250.

29. Berberich, D. W.; Orth, R. G. Proceedings of the 38th Annual
Conference on Mass Spectrometry and Allied Topics; Tucson, 1990; p 871,

30. Eckenrode, B. A.; McLuckey, S. A.; Glish, G. L. Proceedings of the 38th Annual Conference on Mass Spectrontetry and Allied Topics; Tucson, 1990; $\mathrm{p} 869$

31. Eckenrode, B. A.; Glish, G. L.; McLuckey, S. A. Int. I. Mass Spectrom. Ion Processes 1990, 99, 151.

32. Dawson, P. H. Quadrupole Mass Spectrometry and Its Applications; Elsevier: Amsterdam, 1976; $\mathbf{p} 1$.

33. Todd, J. H. J. In Lynamtc Mass Spectrometry; Price, D.; lodd, J. F. J., Eds.; Heyden: London, 1981; p 44.

34. Dillard, J. G. Chem. Rev. 1973, 73, 589.

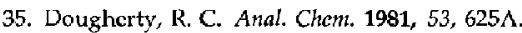

36. Pedder, R. E.; Yost, R. A. Proceedings of the 36th Annual Conference on Mass Spectrometry and Allied Topics; San Francisco, 1988, p 632.

37. Stafford, G. C.; Reeher, J. R.; Smith, R. D.; Story, M. S. In Dynamic Mass Spectrometry; Price, D.; Todd, J. F. J., Eds.; Heyden: London, 1978; Vol. 5, p 55.

38. Bradenberger, H. In Recent Developments in Mass Spectrometry in Biochernistry and Medicine; Frigerio, A., Ed.; Plenum: New York, 1979; p 85.

39. Chapman, J. R. Practical Organic Mass Spectrometry; Wiley: New York, 1985; $\mathrm{p} 46$.

40. Jennings, K. R. Anal. Proc. 1980, 18, 320.

41. Harrison, A. G. Chemical Ionization Mass Spectrometry; CRC Press: Boca Raton, FL, 1983; p 1

42. Dougherty, R. C; Daulton, J.; Biros, F. J. Org. Mass Spectrom. $1972,6,1171$

43. Boand, G.; Houriet, R, Caumann, $T$. In Advances In Mass Spectrometry; Quayle, A., Ed.; Heyden: London, 1980; Vol. 8A, $\mathrm{p} 238$.

44. Melton, C. E. J. Chem. Phys. 1972, 57, 4218.

45. Smit, A. L. C.; Field, F. H. J. Am. Chem. Soc. 1977, 99, 6471.

46. Asano, K. G.; Goeringer, D. E.; McLuckey, S. A.; Hockman, D.; Stiller, S. W. Proceedings of the 41 st Annual Conference on Mass Spectrometry and Allied Topics; San Francisco, 1993; p $700 \mathrm{a}$

47. Shaffer, B. A.; Karnicky, J.; Buttrill, Jr., S. E. Procedings of the 41 st Annual Conference on Mass Spectrometry and Allied Topics. San Francisco, 1993, p 802a. 